\title{
Thriving, Not Just Surviving as a Female STEM Major with ADHD: A Quantitative Analysis of Cumulative G.P.A.
}

\author{
Nicole Nicholson
}

\begin{abstract}
In an effort to examine the academic functioning of college students with ADHD, a significant number of females with ADHD in Science, Technology, Engineering, and Mathematics (STEM) majors volunteered to take part in a quantitative study at two highly selective 4-year universities. Data analysis was used to determine whether female participants with ADHD in STEM majors were achieving at the same level as their STEM ADHD male and non-STEM female counterparts. A convenience sample of 27 college students with ADHD completed the ADHD Indicator Survey created by the Primary Investigator. Statistical analysis of G.P.A. self-reported by students indicated that there was not a significant difference between the mean G.P.A. of females with ADHD majoring in STEM and females with ADHD who were non-STEM majors. There also failed to be a significant difference between the G.P.A.'s of ADHD STEM females and males with ADHD in STEM. Interestingly, the G.P.A.'s of males in a STEM major with ADHD differed significantly from that of ADHD males pursing a non-STEM major. These results suggested that women with ADHD were just as academically successful as males with ADHD in a STEM major and females with ADHD in non-STEM majors.
\end{abstract}

Index Terms-Attention-deficit/hyperactivity disorder (ADHD), science, technology, engineering, and mathematics (STEM), academic achievement.

\section{INTRODUCTION}

Significant efforts have taken place over the course of the last two decades to address the underrepresentation of women and persons with disabilities in STEM at the post-secondary level. In recent years, the number of women earning degrees in STEM has been increasing; however, men continue to earn the majority of degrees in engineering, physics, computer science, and math [1]. Much of the research in these areas have focused on either a shortage of women in STEM [2] or the fact that persons with various disabilities are less likely to be pursing a STEM major [3], [4] However, fewer studies have focused on academically successful STEM females with a high-incidence disability such as ADHD. As a result, it is unclear how these women are performing academically compared to males with ADHD majoring in a STEM field, or females with ADHD in a non-STEM major. Presently, a literature gap continues to exist with regard to how female STEM majors with ADHD are functioning academically at the post-secondary level

Manuscript received October 31, 2017; revised May 15, 2018.

The author is with the Brandman University, 16355 Laguna Canyon Road, Irvine, CA 80305 USA (e-mail: nnichols@brandman.edu). compared to their ADHD peers.

The original intent of this study was to assess and compare the executive and academic functioning of adult college students with ADHD. Upon recruitment for the study, it was observed that a significant number of the participants were females with ADHD majoring in a STEM field. Being that females with ADHD have been a significantly underrepresented population in STEM, closer examination of their performance data as it compares to their peers at the college level was warranted. Data from these participants were disaggregated and analyzed in order to gain more insight into the academic functioning of females with ADHD in STEM. The intent was to compare the self-reported G.P.A.'s of female STEM majors with ADHD to the following groups: 1. Females with ADHD majoring in a non-STEM field (non-STEM ADHD females) and 2. Males with ADHD majoring in a STEM field (ADHD STEM males).

Research Questions

1) Is there a significant difference between the G.P.A.'s of female STEM majors with ADHD and female non-STEM majors with ADHD?

2) Is there a significant difference between the G.P.A.'s of female STEM majors with ADHD and male STEM majors with ADHD?

\section{LITERATURE REVIEW}

In spite of a nationwide push to encourage and recruit students to pursue majors in Science, Technology, Engineering, or Mathematics (STEM) in the United States [2] the number of individuals actually entering one of these majors and completing the degree remain a concern; especially in the case of women. Even though female presence in higher education has surpassed that of males in recent decades [5], this proliferation has not yet resulted in the proportional representation of women in science or math [1], [2]. Though it remains important that solid efforts continue to recruit women in STEM, the need to analyze the academic performance of women who are already in a STEM major is equally justified.

When it comes to a shortage of women in STEM majors, insufficient presence of additional diverse groups has also been a concern for many years. Historically, students with disabilities [3], [4] have not been as likely to pursue a STEM major, but this is changing according to the National Science Board [1]. Though the proportion of students with disabilities in a STEM major was similar to those in another major area, 
the average undergraduate with a disability in STEM was slightly older and more likely to attend a 2-year institution [1].

While representation from diverse groups is improving, many students with high-incidence disabilities (like ADHD) continue to encounter obstacles that prevent them from being academically successful and/or persisting in a STEM major. Though the exact reasons for this remain uncertain, potential explanations have been proposed related to institutional culture and student support. For example, if some instructors view ADHD as a problem with motivation or an excuse to get out of completing assignments, students with ADHD may not get the encouragement or support they need to pursue STEM majors and persist in these programs [4]. While research has offered valuable information suggesting potential causes for the lack of pursuit and persistence in STEM by those with disabilities, questions remain regarding the academic functioning of those with disabilities who have already accomplished this feat.

Much attention and focus have been devoted to the shortage of women in STEM and students with disabilities in STEM. However, literature on women with disabilities who are STEM majors in good academic standing is lacking to an even greater degree. Due to knowledge and literature gaps within these areas, the aim of this study was to analyze the academic functioning of STEM females with ADHD and compare it to their male, STEM ADHD and female, non-STEM ADHD counterparts.

\section{METHOD}

\section{A. Participants}

Using convenience sampling at one large, urban, private university in California and one smaller rural university in California, a call for participants requested adult volunteers with ADHD to take part in this quantitative study. To achieve an adequate sample size, this study consisted of 27 ADHD participants 18 years of age or older. In order to take part in the study as an ADHD participant, each individual had an ADHD diagnosis based on Diagnostic and Statistical Manual of Mental Disorders (DSM) criteria by a mental health professional such as a medical doctor or clinical psychologist. Of the 27 participants with ADHD, 12 were STEM majors and 15 were non-STEM majors. The goal was to achieve a near 50-50 split between male and female participants. Therefore, 12 participants were female and 15 were male. There were a total of 6 female STEM majors with ADHD and 6 female Non-STEM majors with ADHD. 6 males with ADHD also majored in STEM, while 9 male participants were Non-STEM majors (see Table I).

Demographically, the sample consisted predominantly of Caucasian volunteers $(66.67 \%) .11 .1 \%$ of the sample were Latino, while Caucasian/Hispanic and Asian participants each represented $7.4 \%$ of participants. $3.7 \%$ of participants were African American and $3.7 \%$ were Persian students (see Table II).

\section{B. Measures}

In this study, academic functioning was measured by participants' self-report of cumulative G.P.A. Each participant completed the ADHD Indicator Survey consisting of approximately 15 questions. These questions were designed to collect demographic and academic data. The questionnaire was created by the primary investigator and reviewed by the clinical psychologist overseeing the study.

\section{Data Analysis}

To analyze the proposed research questions, a descriptive, quantitative research design was used. Data were disaggregated by major and gender. This design was chosen in order to compare the G.P.A's of female STEM majors to female, non-STEM majors with ADHD and male STEM majors with ADHD. Using self-reported cumulative G.P.A. as the academic performance indicator, a between groups comparison was made. In order to determine between group differences and address each research question, a two-sample t test was used with $\alpha$ of 0.05 as a threshold. It was assumed that there were no significant differences between groups.

\section{RESUlTS}

To address each research question posed, data analysis of G.P.A. was analyzed for between group differences using two-sample t-tests. Mean G.P.A.'s for all groups are shown in Table III \& Fig. 1. The mean G.P.A. for ADHD STEM females ( $\mathrm{n}=6$ ) was 2.967 ( $S D=0.612), 2.800$ for Non-STEM ADHD females $(n=6)(S D=0.537), 2.533$ for ADHD STEM males $(\mathrm{n}=6)(S D=0.450)$, and 3.2 for Non-STEM ADHD males $(\mathrm{n}=9)(S D=0.583)$.

Prior to analyzing between group differences, a Bonferoni Test for Equal Variances was used to ensure that the sample distribution was normal. A two-sample t-test was then used to analyze between group differences in mean G.P.A. The results of the test for significance revealed that Non-STEM ADHD female G.P.A. did not differ significantly from the G.P.A.'s of females with ADHD who were STEM majors $(p=0.628)$. This result indicated with female STEM majors with ADHD possessed a grade point average that was comparable to that of females with ADHD who were majoring in a non-STEM field (See Table IV and Fig. 2).

In addition, no significant difference was observed between the G.P.A.'s of women with ADHD majoring in STEM and their ADHD male, STEM colleagues $(\mathrm{p}=0.196)$. This result suggested that the grades of STEM females with ADHD were similar to males with ADHD also majoring in a similar field. Results of this analysis are shown in Table 4.

Though a research question was not originally posed to assess the G.P.A.'s of males with ADHD majoring in STEM and non-STEM fields, statistical analysis indicated that these two groups differed significantly $(\mathrm{p}=0.028)$. The G.P.A. of males with ADHD in a non-STEM major appeared to be higher than that of males with ADHD in a STEM major (see Table IV).

Literature on the academic functioning of STEM students at the post-secondary level possessing ADHD is minimal. Because females tend to be less likely to pursue certain STEM majors in college than males [6] even less research is available on this population. How these women are functioning academically at the college level compared to 
their peers remains in question, but these results shed some light on this topic.

Between groups comparisons were run in order to determine how the G.P.A. of women with ADHD in STEM compared to those of male STEM majors also possessing the disorder. Data analysis indicated that there was no significant difference between the groups, thus suggesting that women with ADHD in STEM were doing just as well academically as their male ADHD counterparts.

TABLE I: PARTICIPANTS WITH ADHD BY GENDER AND MAJOR

\begin{tabular}{lllll}
\hline \hline & & & Medi \\
Gender & STEM & Non-STEM & $\begin{array}{l}\text { an } \\
\text { Age }\end{array}$ & Age Range \\
\hline ADHD Male & 6 & 9 & 21 & $19-31$ \\
ADHD Female & 6 & 6 & 21 & $19-45$ \\
Total & 12 & 15 & 21 & $19-45$ \\
\hline \hline
\end{tabular}

TABLE II: DEMOGRAPHICS OF ADHD PARTICIPANTS

\begin{tabular}{lll}
\hline \hline Ethnicity & Male & Female \\
\hline Caucasian & 11 & 7 \\
Caucasian/Hisp & 1 & 1 \\
Asian & 1 & 1 \\
African American & 0 & 1 \\
Latino/a & 1 & 2 \\
Persian & 1 & 0 \\
\hline \hline
\end{tabular}

TABLE III: COMPARISON OF MEAN G.P.A. FOR ALL GROUPS

\begin{tabular}{lll} 
Group & $\begin{array}{l}\text { Mean } \\
\text { G.P.A. }\end{array}$ & $\begin{array}{l}\text { Standard } \\
\text { Deviation }\end{array}$ \\
\hline $\begin{array}{l}\text { STEM ADHD } \\
\text { Females }\end{array}$ & 2.967 & 0.612 \\
$\begin{array}{l}\text { STEM ADHD } \\
\text { Males }\end{array}$ & 2.533 & 0.450 \\
$\begin{array}{l}\text { Non-STEM } \\
\text { ADHD Females }\end{array}$ & 2.800 & 0.537 \\
$\begin{array}{l}\text { Non-STEM } \\
\text { ADHD Males }\end{array}$ & 3.200 & 0.583 \\
\hline \hline
\end{tabular}

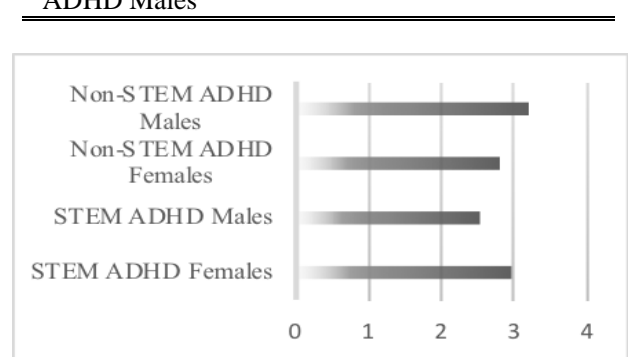

Fig. 1. Mean G.P.A. of Participants by Group.

TABLE IV: RESULTS OF TwO-SAMPLE T-TESTS OF SIGNIFICANCE

\begin{tabular}{ll}
\hline \hline Between Groups Comparison & $p$-value \\
\hline $\begin{array}{l}\text { STEM ADHD Females \& } \\
\text { Non-STEM Females }\end{array}$ & 0.628 \\
STEM ADHD Females \& & \\
STEM ADHD Males & 0.196 \\
$\begin{array}{l}\text { STEM ADHD Males and } \\
\text { Non-STEM ADHD Males }\end{array}$ & 0.028 \\
\hline \hline
\end{tabular}

In addition to female STEM majors having G.P.A.'s that were comparable to those of males with ADHD in STEM, no significant difference was found between the G.P.A.'s of STEM and non-STEM females with ADHD. This finding indicates that a female STEM major with ADHD can have the same (or higher) G.P.A. as a female with ADHD majoring in an area other than STEM.

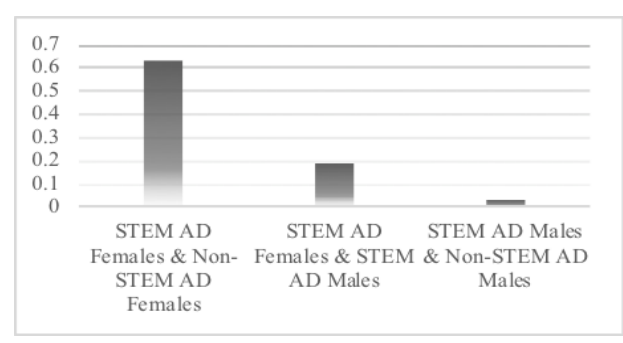

Fig. 2. Two-sample t-tests of significance P-values.

\section{Discussion}

The representation of women and students with disabilities in STEM majors at 4-year universities is improving, yet men continue to earn the majority of undergraduate degrees in science, math, and computer science [1], Being that females and students with disabilities historically have not been as likely to obtain a degree in a STEM field [7], this study served to examine the academic achievement of women with ADHD who were well on their way to earning a degree in one of these areas. A comparison of these individuals' levels of academic functioning was necessary in order to determine if those women persisting in STEM with ADHD were performing at a level similar to that of their peers.

\section{A. Research Question \#1}

Because women with a disability may be less likely to persist in a STEM major and are more likely to switch majors to a non-STEM field, many would assume that the overall G.P.A. of women with ADHD in a non-STEM major would be higher than her ADHD STEM counterpart. Analysis of data in this study failed to confirm that assumption. Due to the fact that a significant difference was not observed in mean G.P.A., it was concluded that females with ADHD in STEM majors taking part in this study had a G.P.A. that was comparable to female non-STEM majors with ADHD. This finding provides support and encouragement for women with ADHD who are enrolled in or interested in pursuing a STEM major.

\section{B. Research Question \#2}

STEM majors have been historically male [8], [2] but this is changing. In addition, the amount of representation of students with disabilities is also improving [1]. In spite of these improvements, increased diversity within these fields remains a significant need. With more students possessing a disability in fields that have traditionally been predominantly male, it could hypothesized that males with ADHD in STEM would have a significantly higher G.P.A. than a women with the same condition in a similar major. This study failed to confirm a significant difference between the G.P.A. of a woman with ADHD in STEM and her ADHD male, STEM colleague. As a result, findings in this study are contradictory to a significant amount of research that has exposed trends that paint less than ideal picture for female students with disabilities who might be interested in majoring in math or engineering. Again, this is an encouraging finding for women with ADHD who are looking to STEM as a possible major.

There are a vast number of factors that influence one's success or failure within an academic field. The reasons 
behind why women and students with disabilities continue to be underrepresented in certain STEM fields such as engineering and mathematics cannot be completely explained. It has been hypothesized that social and/or learning cultures in STEM appeal more to men [7], female role models in STEM are lacking [9] gender stereotypes prevail, supports are insufficient, and students with certain disabilities may be viewed in a negative light by professors [4]. In spite of these potential obstacles, the women with ADHD majoring in STEM in this study were rather successful academically. This group of participants was doing just as well academically as every group to which they were compared. Because of these findings, questions arose regarding the potential reasons behind the success of these participants. Due to the quantitative nature of this study, the answers to these questions could not be ascertained.

A research question was not posed in this study to examine differences between male ADHD STEM and non-STEM majors. However, the significant difference in mean G.P.A. between these two groups was an interesting finding as well. Why the G.P.A. of males with ADHD in a non-STEM major was higher on average than STEM majors also remains in question. Of all groups in the study with ADHD, males who were non-STEM did possess the highest mean G.P.A. based on student report.

\section{Limitations and Suggestions for Future Research}

A number of limitations must be noted when interpreting the results of this study. First, the initial intent of the study was to recruit students with ADHD to examine executive as well as academic functioning. Upon review of demographic data, it was observed that a large number of participants volunteering for the study were STEM majors. However, sample sizes remained small. Replication of the study using a larger sample size would be suggested. In addition to a larger sample size, a more diverse sample would also be ideal. The majority of participants in this study were Caucasian. Greater insight could be gained from analyzing data from a more ethnically diverse sample of participants.

Another limitation has to do with the schools from which subjects were recruited. These two universities in California were considered to be highly selective 4-year institutions known for renowned STEM programs. It could be that students in this study developed compensation strategies long ago that helped them achieve academic success, were receiving extensive support services, belonged to majors where diverse students felt supported, or were not your 'typical' college student at an average university. Replication of the study at a larger number of universities across the country with varying levels of selectivity for admission would be recommended.

The final limitation of the study was the reliance on student honesty and self-disclosure of overall grade point average. Though surveys were taken privately with numbers used for identification and group assignment purposes, it was possible for a student to be dishonest about their true G.P.A. This could be remedied by acquiring consent for review of academic records or transcripts.

\section{CONCLUSION}

The significant literature gap and need for more diverse representation in certain STEM fields warrants further research in this area. Though this study found that women with ADHD in STEM fields were performing equally as well as their ADHD peers, further investigation is needed. Exactly what these students have done in the past and do in the present to remain in good academic standing would be valuable information to acquire. A mixed-methods approach examining the traits, practices, and strategies exhibited by females with ADHD who are successfully thriving in STEM majors is suggested. While a focus on deficits within STEM is important, there is a great need for researchers to determine if there are common themes, habits, or skills exhibited by successful females with ADHD who are already majoring in STEM. Such data could also offer insight into how schools or STEM programs are attracting and retaining female students with ADHD. In conclusion, females with a disability in many STEM majors remain rare. Much could be learned from these women as we attempt to address a shortage of females and students with disabilities in STEM. To address this area of need, researchers must look to those who have already accomplished exactly what we are attempting to facilitate.

\section{REFERENCES}

[1] National Science Board, Science and Engineering Indicators 2016. Arlington, VA: National Science Foundation (NSB-2016-1), 2016.

[2] C. A. Shapiro and L. J. Sax, "Major selection and persistence for women in STEM," New Directions for Institutional Research, 2011, pp. $5-18$.

[3] J. L. White and G. H. Masshiha, "Strategies to increase representation of students with disabilities in science, technology, engineering, and mathematics," International Journal of Evaluation and Research in Education, vol. 4, no. 3, pp. 89-93, 2015.

[4] C. Dunn, K. S. Rabren, S. L. Taylor, and C. K. Dotson, "Assisting students with high-incidence disabilities to pursue careers in science, technology, engineering, and mathematics," Intervention in School Clinic, vol. 48, no. 1, 47-54, 2012.

[5] J. G. Gayles and F. Ampaw, "The impact of college experiences on degree completion in STEM fields at four-year institutions: Does gender matter?" The Journal of Higher Education, vol. 85, no. 4, pp. 439-468, 2014.

[6] A. Lee, "Students with disabilities choosing science technology engineering and math (STEM) majors in postsecondary institutions," Journal of Postsecondary Education and Disability, vol. 27, no. 3, pp. 261-272, 2014.

[7] M. Soldner et al., "Supporting students' intentions to persist in STEM disciplines: The role of living learning programs among other social-cognitive factors," The Journal of Higher Education, vol. 83, no. 3, pp. 311-336, 2012.

[8] R. Su and J. Rounds, "All STEM fields are not created equal: People and things interests explain gender disparities across STEM fields," Frontiers in Psychology, vol. 6, p. 189, 2015.

[9] D. N. Beede et al., "Women in STEM: A gender gap to innovation," Economics and Statistics Administration Issue Brief No. 04-11, 2011.

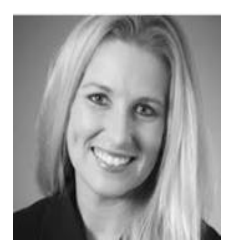

Nicole Nicholson completed her doctor of education degree with an emphasis in educational psychology at the University of Southern California, Los Angeles. She has devoted her academic and professional career to serving students with special needs. Most of her research has been in the area of attention-deficit/hyperactivity disorder and how the condition impacts executive and academic functioning. Dr. Nicholson is an education specialist and Educational therapist with the Association of Educational Therapists. She has completed visiting fellowships in $f$ MRI at the Martinos Center for Biomedical Imaging in Boston, M.A. and the M.I.N.D. Institute at New Mexico State University. 